\title{
Regional Cerebral Blood Flow During Gastric Balloon Distention in Functional Dyspepsia
}

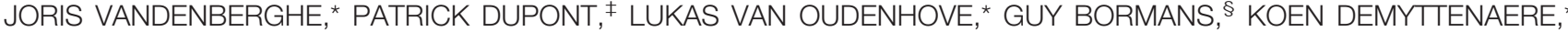 \\ BENJAMIN FISCHLER, * BRECHT GEERAERTS," JOZEF JANSSENS," and JAN TACK," \\ ${ }^{*}$ Department of Psychiatry, Division of Liaison Psychiatry, ${ }^{\ddagger}$ Department of Nuclear Medicine, ${ }^{\S}$ Department of Radiopharmacy, and "Department of Internal Medicine, \\ Division of Gastroenterology, University Hospital Gasthuisberg, Katholieke Universiteit Leuven, Leuven, Belgium
}

See Sayuk GS et al on page 556 in the May 2007 issue of $\mathrm{CGH}$

Background \& Aims: Hypersensitivity to proximal gastric distention as a result of abnormal central nervous system processing of visceral stimuli is a possible pathophysiologic mechanism in functional dyspepsia (FD). Increasing evidence suggests involvement of both lateral and medial pain systems in normal visceral sensitivity and aberrant brain activation patterns in visceral hypersensitivity. We hypothesized that there is involvement of aberrant brain activation in FD with hypersensitivity to gastric distention. Our aim was to investigate regional cerebral blood flow during painful proximal gastric distention in hypersensitive FD. Methods: Brain ${ }^{15} \mathrm{O}$-water positron emission tomography was performed in 13 FD patients with symptoms of gastric hypersensitivity during 3 conditions: no distention, sham distention, and isobaric distention to unpleasant or painful sensation. Pain, discomfort, nausea, and bloating during maximal distention were rated on visual analogue scales. Data were analyzed using statistical parametric mapping. Results: The threshold for painful distention was $6.6 \pm 3.8 \mathrm{~mm} \mathrm{Hg}$ greater than the minimal distending pressure. At the corrected $P$ level of less than .05 , subtraction analysis (painful distention - no distention) showed activations in bilateral gyrus precentralis, bilateral gyrus frontalis inferior, bilateral gyrus frontalis medialis, bilateral gyrus temporalis superior, bilateral cerebellar hemisphere, and left gyrus temporalis inferior. Sham distention minus no distention showed no activations. Conclusions: Similar to healthy volunteers, proximal stomach distention in FD activates components of the lateral pain system and bilateral frontal inferior gyri, putatively involved in regulation of hunger and satiety. In hypersensitive FD, these activations occur at significantly lower distention pressures. In contrast to findings in nor- mosensitivity, none of the components of the medial pain system were significantly activated.

$\mathrm{V}$ isceral hypersensitivity, a condition characterized by lowered thresholds for discomfort, pain, or other sensations during intraluminal balloon distention, has been shown in several functional gastrointestinal disorders including functional dyspepsia (FD), ${ }^{1,2}$ irritable bowel syndrome (IBS), ${ }^{3}$ and noncardiac chest pain. ${ }^{4} \mathrm{Pe}-$ ripheral changes at the level of the gastrointestinal tract as well as alterations at the level of the central nervous system may contribute to the pathogenesis of visceral hypersensitivity. ${ }^{5}$

The evidence for hypersensitivity to proximal gastric distention in FD is substantial. Several studies have shown that up to two thirds of patients with FD report discomfort or pain at lower thresholds of intragastric balloon distention than healthy controls..$^{1,2,5-9}$ In a large patient series, gastric hypersensitivity was found to be associated with a higher prevalence of postprandial epigastric pain, belching, and weight loss. ${ }^{7}$ This association with a distinct FD symptom pattern is supportive of a role for hypersensitivity to proximal stomach distention in the pathogenesis of FD symptoms. In a factor analysis of pathophysiologic and psychosocial features of FD, we found that gastric hypersensitivity was associated with several psychologic variables including the presence of anxiety, somatization, neuroticism, and a history of abuse. ${ }^{10-12}$ The interaction with psychopathologic variables was found to statistically mediate the association between upper-abdominal pain and gastric hypersensitivity. ${ }^{10}$ These observations suggest that abnormal central nervous system processing of gastric stimuli may be a relevant pathophysiologic mechanism in FD.

Abbreviations used in this paper: ACC, anterior cingulate cortex; BA Brodmann area; FD, functional dyspepsia; IBS, irritable bowel syndrome; MRI, magnetic resonance imaging; PET, positron emission tomography; VAS, visual analogue scale.

(C) 2007 by the AGA Institute 0016-5085/07/\$32.00 doi:10.1053/j.gastro.2007.03.037 
The central nervous system structures involved in processing normal sensitivity to gastric distention have been partially elucidated. ${ }^{13-16}$ Painful gastric distention in healthy volunteers has been shown to activate a similar set of brain structures as activated in somatic pain, including the right insula and the right midanterior cingulate cortex. The frontal inferior gyrus (Brodmann area [BA] 47) seems to play a unique role in processing stimuli involving the proximal stomach, ${ }^{13,15,16}$ as opposed to other visceral or somatic stimuli. It is proposed as a convergence zone for processing food-related stimuli. ${ }^{14}$ Increasing evidence links the frontal inferior gyrus, particularly the right side, to the regulation of hunger, appetite, satiety, and food intake. ${ }^{17-23}$

In IBS, another condition associated with visceral hypersensitivity, functional brain imaging studies revealed differences in cerebral activation during rectal distention in IBS compared with healthy volunteers, suggestive of abnormal central nervous system processing of visceral stimuli. ${ }^{24-26}$ We hypothesized that FD patients with hypersensitivity to gastric distention also would display altered brain activation patterns during distention of the proximal stomach.

The aim of this study was to describe the brain regions activated by actual painful distention of the proximal stomach in FD with gastric hypersensitivity, and the brain regions activated by sham distention. Furthermore, this study aimed to contribute to the characterization of brain activation patterns and specific neurocircuitry associated with visceral hypersensitivity, to the elucidation of gastric sensory processing in FD, and to the understanding of the physiopathology of gastric hypersensitivity. For the latter purpose, we compared the data of the present study with recently reported findings obtained from healthy volunteers using a similar study design. ${ }^{15}$

\section{Materials and Methods Subjects}

Thirteen FD patients ( 3 men; mean age, $30.6 \pm$ 8.2 y) were recruited for the study (Table 1 ). They were selected on the basis of demonstrated gastric hypersensitivity in a previous barostat examination $(\mathrm{n}=8)$ or on the basis of a symptom pattern suggestive of gastric hypersensitivity, with epigastric pain as the predominant symptom $(\mathrm{n}=5)$. Hypersensitivity, defined as a threshold for pain or unpleasantness of less than $6.4 \mathrm{~mm} \mathrm{Hg}$ above minimal distending pressure, ${ }^{7}$ was confirmed in 3 patients of the latter group. The most prevalent symptom was postprandial fullness $(92 \%)$, followed by pain $(85 \%)$, bloating (85\%), nausea (77\%), and belching (69\%). Early satiety was present in $62 \%$ of the patients, whereas $54 \%$ complained of epigastric burning and 38\% reported vomiting. Nine patients $(69 \%)$ reported weight loss of more than $5 \%$ of their original body weight (average, $8.2 \pm 2.5$ $\mathrm{kg}$ weight decrease). All patients were Helicobacter pylori
Table 1. Comparison of Healthy Volunteers and Hypersensitive FD Patients

\begin{tabular}{lccc}
\hline & $\begin{array}{c}\text { Healthy volunteers } \\
(\mathrm{n}=11)\end{array}$ & $\begin{array}{c}\text { FD patients } \\
(\mathrm{n}=13)\end{array}$ & $P$ value \\
\hline Age & $23.1 \pm 1.7$ & $30.6 \pm 8.2$ & .008 \\
Sex distribution (\% males) & 45.5 & 23.1 & .21 \\
$\begin{array}{l}\text { Threshold for painful or } \\
\quad \text { unpleasant sensation }\end{array}$ & & & \\
$\quad$ (mm Hg above minimal & & & \\
$\quad$ distending pressure) & $11.3 \pm 3.4$ & $6.6 \pm 3.8$ & .004 \\
0-6 rating scale score for & & & \\
$\quad$ highest distention & & & \\
$\quad$ during PET experiment & $4.7 \pm 0.5$ & $5.2 \pm 0.5$ & .07 \\
VAS score for pain & $5.0 \pm 2.1$ & $8.0 \pm 2.5$ & .39 \\
VAS score for discomfort & $6.6 \pm 1.4$ & $8.2 \pm 1.1$ & .44 \\
VAS score for nausea & $3.2 \pm 2.8$ & $6.2 \pm 3.2$ & .28 \\
VAS score for bloating & $8.1 \pm 0.9$ & $7.5 \pm 3.2$ & .67 \\
VAS score for anxiety & & & \\
$\quad$ immediately after PET & & & \\
$\quad$ experiment & $1.7 \pm 1.3$ & $1.6 \pm 2.3$ & .45 \\
VAS score for tension & & & \\
$\quad$ immediately after PET & & & \\
$\quad$ experiment & $2.0 \pm 1.4$ & $2.3 \pm 2.9$ & .37 \\
\hline
\end{tabular}

NOTE. Healthy volunteer data are from Vandenberghe et $\mathrm{al}^{15}$ and hypersensitive FD patient data are from the present study. Data were compared with regard to age and sex distribution, maximal distention threshold, symptom scores during maximal distention, and tension and anxiety immediately after PET experiment.

negative. Patients on psychotropic drugs were excluded from the study. All other medications potentially influencing gastrointestinal motility and sensitivity (mainly prokinetic and antinausea drugs) were discontinued at least 24 hours before study participation. None of the patients had a history of a nonfunctional gastrointestinal disease. All study procedures were undertaken with the understanding of and after obtaining written consent from each subject, in accordance with the Declaration of Human Rights (Helsinki, 1975). The protocol had been approved previously by the ethical committee of the University Hospital.

\section{Barostat Procedure}

After an overnight fast of at least 12 hours, and 2 hours before positron emission tomography (PET) imaging, a double-lumen polyvinyl tube (Salem sump tube $14 \mathrm{Ch}$; Sherwood Medical, Petit Rechain, Belgium) with a finely folded adherent plastic bag (capacity, $1200 \mathrm{~mL}$; maximal diameter, $17 \mathrm{~cm}$ ) was introduced through the mouth and secured to the subject's chin with adhesive tape. The position of the bag in the proximal stomach was checked fluoroscopically. The polyvinyl tube then was connected to a programmable barostat device (Barostat Distender Series II; G\&J Electronics Inc., Toronto, Ontario, Canada). To unfold the bag, it was inflated with a fixed volume of $300 \mathrm{~mL}$ of air for 2 minutes with the study subject in a recumbent position and again deflated. The subjects then were positioned in the same condition as under the PET 
scanner, comfortably lying down (supine position) with slightly bent knees. Pilot studies with fluoroscopy control established that balloon distention occurs in the proximal stomach in this position. After a 30minute adaptation period, the minimal distending pressure was first determined by increasing the intrabag pressure by $1 \mathrm{~mm} \mathrm{Hg}$ every minute until a volume of $30 \mathrm{~mL}$ was reached. ${ }^{7}$ This pressure level equilibrates the intra-abdominal pressure. To assess individual perception thresholds, isobaric distentions were performed in double-random staircase increments of 2 $\mathrm{mm} \mathrm{Hg}$ starting from the minimal distending pressure, each lasting for 2 minutes, while the corresponding intragastric volume was recorded. Subjects were instructed to score their perception of upper-abdominal sensations at the end of every distending step using a graphic rating scale that combined verbal descriptors on a scale graded $0-6 .^{7}$ The end point of each sequence of distentions was established when the subjects reported discomfort or pain (score, 5 or 6). From the double-random staircase distentions, we obtained the individual's pressure thresholds for unpleasant or painful sensations (mean pressure inducing score, $\geq 5$ ). Then the balloon was deflated and the subject and barostat device were transferred to the PET scanner, where the subject was installed in the same supine position with slightly bent knees and with the head positioned in the scanner ring.

\section{Psychologic Measures}

Immediately before and after the PET experiment, subjects were asked to complete visual analogue scales (VAS) $(0-10)$ for anxiety and tension, ranging from "not anxious (tense) at all" to "most anxious (tense) I have ever felt.”

\section{Statistical Analysis}

All demographic, physiologic, and psychologic measures were analyzed using SPSS software (SPSS Inc, Chicago, IL). All data are given as mean \pm SD.

\section{PET/Regional Cerebral Blood Flow Imaging}

Conditions. Brain ${ }^{15} \mathrm{O}$-water PET was performed during 3 conditions: (C1), no distention (baseline condition); (C2), actual distention to the individual thresholds for unpleasant or painful sensations (maximal distention) as determined in the preceding barostat procedure; and (C3), sham distention or simulated delivery of an anticipated stimulus. Just before the sham distention, the subject was instructed that a distention would follow, but during this condition no actual balloon distention was applied. Each condition was replicated 4 times in a pseudorandomized block design. Gastric sensation was rated with the same $0-6$ graded graphic rating scale immediately after each distention. Pain, discomfort, nausea, and bloating during the most intense distention were rated retrospectively on a VAS $(0-10)$ immediately after the PET experiment.

Data acquisition. Brain activity was monitored as the relative change in regional cerebral blood flow using the $\mathrm{H}_{2}{ }^{15} \mathrm{O}$ method. ${ }^{27}$ All measurements were performed in 3-dimensional mode with a Siemens-Cti Ecat Exact $\mathrm{Hr}+$ (Siemens, Erlangen, Germany). ${ }^{28}$ The room was kept as quiet as possible. Each subject's head was immobilized with a foam head holder (Smither Medical Products, Akron, $\mathrm{OH})$. Each subject had a catheter inserted into the left brachial vein for tracer administration. A transmission scan was taken $\left({ }^{68} \mathrm{Ge} / \mathrm{Ga}\right.$ rod sources) to correct for attenuation. The following procedure then was repeated 12 times $(12$ scans; 4 conditions each replicated 3 times in each subject): 1 minute after starting intragastric balloon inflation (if applicable), an intravenous injection of $300 \mathrm{MBq} \mathrm{H}_{2}{ }^{15} \mathrm{O}$ (half-life, 123 seconds) was administered over 12 seconds. There was at least a 10-minute interval between 2 successive injections. Data acquisition (60 seconds) began as soon as the intracranial radioactivity count rate increased sharply (ie, usually about 40-60 seconds after the start of the injection). The intragastric balloon was deflated immediately after completion of the data acquisition. It was kept deflated in-between periods of data acquisition and during the baseline condition. The attenuation-corrected data were reconstructed using the re-projection algorithm. ${ }^{29}$ The integrated radioactivity counts were used as a measure of regional cerebral blood flow.

Data analysis. Analysis was performed on Sun SPARC computers (Sun Microsystems, Mountain View, CA) with statistical parametric mapping software (Department of Cognitive Neurology, Wellcome, London, England), version SPM2 (http://www.fil.ion.ucl.ac.uk/ $\mathrm{spm} /$ software/spm2/), implemented in MATLAB (Mathworks Inc., Sherborn, MA). The scans from each subject were realigned using the first scan as a reference. The 6 parameters of this rigid body transformation were estimated using a least-square approach. Images then were transformed stereotactically ${ }^{30}$ to the Montreal Neurological Institute template space. Finally, images were smoothed with a 3-dimensional isotropic Gaussian kernel of $16 \mathrm{~mm}$ full width at half maximum. Statistical parametric maps are spatially extended statistical processes used to characterize regionally specific effects in imaging data, combining the general linear model (to create the statistical map of statistical parametric mapping) and the theory of Gaussian fields (to make statistical inferences about regional effects). ${ }^{31-33}$ Global brain activity was fixed arbitrarily at $50 \mathrm{~mL} \mathrm{dL}-1$ $\min ^{-1} .{ }^{34}$ The condition and covariate effects were estimated according to the general linear model at each voxel. 
Contrasts. To determine the activation in the distention and sham conditions relative to baseline, activity in the latter condition was subtracted from that in the distention or sham condition. For each contrast, the resulting set of voxel values constitutes a statistical parametric map of the $t$-statistic statistical parametric mapping $(t)$. For the analysis, the significance threshold was set at $P_{\text {uncorrected }}<.001$ (at the voxel level). However, we considered only those clusters reaching significance at the $P_{\text {FWE-corrected }}<.05$ cluster level (corrected for multiple comparisons using the Family Wise Error Correction in SPM2). These clusters and their respective $P_{\text {corrected }}$ values are listed in Table 2, together with the associated Montreal Neurological Institute coordinates of the corresponding local maxima, the respective $P_{\text {corrected }}$ and $t$ values of these local maxima, its tentative anatomic localization, and the number of voxels in the cluster.

\section{Anatomic Magnetic Resonance Imaging Data}

Each subject underwent a high-resolution anatomic magnetic resonance imaging (MRI) scan using a 3-dimensional magnetization-prepared rapid gradientecho sequence. ${ }^{35}$ Acquisition parameters were as follows: repetition time, $10 \mathrm{~ms}$; echo time, $4 \mathrm{~ms} ; 256-\mathrm{mm}$ field of view; flip angle, $8^{\circ}$; and acquisition matrix, $256 \times 256$. The 3-dimensional volume with $160-\mathrm{mm}$ thickness was partitioned in 160 sagittal slices. MRI images of each subject were registered to the corresponding PET images using multimodality image registration using information theory. ${ }^{36}$ The MRI data were transformed into Montreal Neurological Institute space using the same transformations as those for the PET images. References to the stereotactic atlas of the human brain ${ }^{37}$ combined with MRI data of the subjects were used to help identify the anatomic localization of activations. However, for visualization, the single-subject, high-resolution-rendered MRI available in SPM2 was used as well.

\section{Comparison With Findings Obtained in Healthy Controls}

The side-by-side comparison of the data of the present study with previous findings obtained in healthy volunteers (Tables 1 and 3 ) is based on the high similarity of the protocols of both studies. ${ }^{15}$ Both studies were performed by the same investigator using the same sequence of barostat examination and PET scanning with randomized conditions. Both studied primarily the painful distention vs baseline condition, defined and determined in exactly the same way in both studies. Statistical comparison of patient and healthy volunteer groups with regard to age, thresholds, VAS scores (Table 1), mean absolute PET signal at baseline, and mean percentage difference in PET signal (Table 3) was performed using a 2-sided unpaired $t$ test.

\section{Results}

Distention Parameters, Symptoms Elicited by Distention of the Proximal Stomach, and Psychological Measures

Distention parameters, symptoms elicited by distention of the proximal stomach, and psychologic measures are summarized in the third column of Table 1 . The minimal distending pressure was $6.4 \pm 1.7 \mathrm{~mm} \mathrm{Hg}$. The distending pressures for first (score, $\geq 1$ ), marked (score, $\geq 3$ ), and unpleasant sensation (score, 5 or 6 ) were $2.9 \pm 1.6,4.8 \pm$ 3.1 , and $6.6 \pm 3.8 \mathrm{~mm} \mathrm{Hg}$ greater than the minimal distending pressure, respectively. In 8 subjects, gastric hypersensitivity had been shown previously and, based on previously established normal ranges, 3 of the remaining 5 subjects also were found to be hypersensitive to gastric balloon distention.

The mean 0-6 graded graphic rating scale score for maximal distention during the PET experiment was $5.2 \pm 0.5$, confirming a reliably severe symptom induction during the PET experiment based on the individually predetermined thresholds. The VAS scores for pain, discomfort, nausea, and bloating experienced during maximal distention were $8.0 \pm 2.5,8.2 \pm 1.1,6.2 \pm 3.2$, and $7.5 \pm 3.2 \mathrm{~cm}$, respectively. The symptom score induced by sham distention was $2.3 \pm 1.8$. The VAS scores for anxiety and tension were $2.2 \pm 2.8$ and $2.6 \pm 2.8$, respectively, before PET imaging, and $1.6 \pm 2.3$ and $2.3 \pm$ 2. 9, respectively, after PET imaging.

\section{Regional Brain Activation During Distention of the Proximal Stomach}

Distention vs baseline (C2-C1). The regional brain activation pattern during maximal distention (C2) relative to baseline (C1) is summarized in Table 2. Activation occurred in bilateral gyrus precentralis (BA 4 and 6), bilateral gyrus frontalis inferior (BA 10, BA 44, and BA 47 or orbitofrontal cortex), bilateral gyrus frontalis medialis (BA 10, BA 11), bilateral gyrus temporalis superior (BA 22, BA 38), bilateral cerebellar hemisphere, and left gyrus temporalis inferior (BA 20). These brain activations are shown in Figure 1. Activation in the left insula (coordinate of local maximum $-36,12,-8)$ did not reach significance at the corrected $P$ value $\left(P_{\text {corrected }}=.057\right.$ at cluster level, $P_{\text {corrected }}=.320$ at voxel level, $\mathrm{T}$ value $=4.05$, number of voxels in cluster $=492$ ). No other activation areas showed $P_{\text {corrected }}$ values lower than .1.

Correlation with upper abdominal sensation. To detect which brain activations correlate with upper-abdominal sensations experienced by the subject during each scan, a statistical parametric mapping analysis was performed using the 0-6 graded graphic rating scale score corresponding to each scan as covariate. Overall, the same areas as in the subtraction analysis $(\mathrm{C} 2-\mathrm{C} 1)$ were found (data not shown).

Sham distention vs baseline. A subtraction analysis to detect the regional brain activation pattern during 
Table 2. Statistical Parametric Mapping Analysis of Activation Pattern (Local Maxima and Corresponding Clusters) During Maximal Distention Relative to Baseline (C2-C1)

\begin{tabular}{|c|c|c|c|c|c|}
\hline $\begin{array}{l}\text { Coordinate of } \\
\text { local maximum } \\
(x, y, z \text { in } \mathrm{mm})\end{array}$ & $\begin{array}{c}P_{\text {corrected }} \\
\text { (voxel level) }\end{array}$ & $\begin{array}{c}\text { T-value } \\
\text { (voxel level) }\end{array}$ & Tentative anatomic localization & $\begin{array}{l}\text { Number of voxels in } \\
\text { cluster }\end{array}$ & $\begin{array}{c}P_{\text {corrected }} \\
\text { (cluster level) }\end{array}$ \\
\hline$-68,-6,20$ & .001 & 5.74 & $\begin{array}{l}\text { Left gyrus precentralis (BA } 4,6)+ \text { cluster includes } \\
\text { parts of gyrus postcentralis (BA } 40 \text { ) }\end{array}$ & 2944 & $<.001$ \\
\hline$-56,34,-4$ & .001 & 5.66 & Left gyrus frontalis inferior (BA $10,44,47)$ & & \\
\hline$-54,26,-16$ & .002 & 5.55 & & & \\
\hline$-30,66,-6$ & .004 & 5.38 & & & \\
\hline$-64,8,24$ & .005 & 5.00 & & & \\
\hline$-60,16,-4$ & .013 & 5.06 & & & \\
\hline$-38,50,-20$ & .003 & 5.44 & Left gyrus frontalis medialis (BA 10, 11) & & \\
\hline$-34,62,-12$ & .007 & 5.23 & & & \\
\hline$-64,-8,-32$ & .003 & 5.41 & Left gyrus temporalis inferior (BA 20) & & \\
\hline$-58,14,-18$ & .017 & 4.98 & $\begin{array}{l}\text { Left gyrus temporalis superior (BA } 22,38)+ \text { cluster } \\
\text { includes parts of gyrus precentralis }(B A 4)\end{array}$ & & \\
\hline$-66,2,6$ & .019 & 4.94 & & & \\
\hline$-18,-94,-36$ & $<.001$ & 5.50 & Left cerebellar hemisphere & $\begin{array}{l}3041 \text { (right cerebellar } \\
\text { hemisphere } \\
\text { included) }\end{array}$ & $<.001$ \\
\hline$-26,-86,-44$ & .004 & 5.03 & & & \\
\hline $58,40,-10$ & $<.001$ & 6.51 & Right gyrus frontalis inferior (BA 47) & 2395 & $<.001$ \\
\hline $38,50,-24$ & $<.001$ & 6.12 & $\begin{array}{l}\text { Right gyrus frontalis medialis (BA 11) + cluster } \\
\text { includes parts of } B A 10\end{array}$ & & \\
\hline $50,54,-12$ & .018 & 4.97 & & & \\
\hline $70,6,16$ & $<.001$ & 6.09 & $\begin{array}{l}\text { Right gyrus precentralis (BA } 6)+ \text { cluster includes } \\
\text { parts of gyrus postcentralis }\end{array}$ & & \\
\hline $68,10,0$ & .002 & 5.50 & $\begin{array}{l}\text { Right gyrus temporalis superior (BA 22) + cluster } \\
\text { includes parts of } B A 38\end{array}$ & & \\
\hline $32,-92,-34$ & $<.001$ & 6.81 & Right cerebellar hemisphere & $\begin{array}{l}3041 \text { (left cerebellar } \\
\text { hemisphere } \\
\text { included) }\end{array}$ & $<.001$ \\
\hline
\end{tabular}

NOTE. Analysis was run at the $P_{\text {uncorrected }}<.001$ level and all clusters reaching significance at the $P_{\text {corrected }}<.05$ level are listed. If several local maxima were present within one cluster, the maximum with the highest $t$ value was selected. Other local maxima within the same cluster are only listed if at least $10 \mathrm{~mm}$ apart from the primary maximum and if reaching significance at the $P_{\text {corrected }}<.05$ level. Tentative anatomic localization is given, based on interpretation of the projection of the activation pattern on the MRI images of the subjects, combined with the coplanar stereotaxic atlas of the human brain. Anatomic areas comprising the local maxima are in bold; the adjacent anatomical areas (partly) underlying the corresponding activation cluster as a whole are added in italic.

sham distention relative to baseline (C3-C1) yielded no significant results.

Variability in the patient sample. In the present study, we aimed at reducing heterogeneity in this study by focusing on FD patients with visceral hypersensitivity. To evaluate the amount of regional interindividual PET signal variability in our study sample, we performed a subject-by-subject analysis of the percentage difference in PET signal between distention and baseline (C2-C1) in delineated brain areas, including insular and anterior cingulated cortex (Table 3, fifth column). Those areas were defined as clusters found in healthy volunteers for the corresponding activation. ${ }^{15}$ As shown in Table 3, variability was not greater in the patient sample compared with the healthy volunteers' sample. This is further illustrated in Figure 2, which depicts the individual PET signal percentage difference in the left gyrus postcentralis between maximal distention and baseline for the $13 \mathrm{FD}$ patients.

\section{Comparison With Findings Obtained in Healthy Controls}

To evaluate the specific neurocircuitry involved in gastric hypersensitivity as compared with normal sensitivity, we compared the data of the present study with previous findings obtained from healthy volunteers using a similar protocol ${ }^{15}$ (Tables 1 and 3 ). As expected for FD patients selected for hypersensitivity, the maximum distention threshold was significantly lower in the patient group. Comparison of VAS scores for anxiety, tension, and symptoms during maximal distention showed higher scores for pain, discomfort, and nausea in FD patients, but did not yield significant differences, probably because of the large variability and the small sample size (Table 1). With regard to the brain imaging data, formal comparison by between-group statistical parametric mapping subtraction analysis did not yield any significant results (data not shown). Table 3 compares patients and healthy volunteers with regard to the mean absolute PET signal 
Table 3. Table Comparing Healthy Volunteers and Hypersensitive FD Patients

\begin{tabular}{|c|c|c|c|c|}
\hline \multirow[b]{2}{*}{ Tentative anatomic localization } & \multicolumn{2}{|c|}{ Mean absolute PET signal at baseline } & \multicolumn{2}{|c|}{$\begin{array}{l}\text { Mean percentage difference in PET signal } \\
\text { between maximal distention and baseline }\end{array}$} \\
\hline & $\begin{array}{l}\text { Healthy volunteers } \\
\qquad(\mathrm{n}=11)\end{array}$ & FD patients $(n=13)$ & $\begin{array}{l}\text { Healthy volunteers } \\
\qquad(n=11)\end{array}$ & FD patients $(n=13)$ \\
\hline \multicolumn{5}{|l|}{ Left gyrus postcentralis (BA 43) } \\
\hline (+ cluster includes parts of $B A 4,6)$ & $43.1 \pm 1.3$ & $42.6 \pm 1.2$ & $10.9 \pm 6.2$ & $9.6 \pm 3.7$ \\
\hline \multicolumn{5}{|l|}{ Left gyrus temporalis superior (BA 38) } \\
\hline (+ cluster includes part of BA 47) & $37.7 \pm 1.9$ & $37.2 \pm 1.3$ & $14.0 \pm 12.2$ & $12.3 \pm 4.4$ \\
\hline Left cerebellar hemisphere, posterior & $40.8 \pm 1.0$ & $42.2 \pm 2.2$ & $8.7 \pm 2.0$ & $11.1 \pm 3.3$ \\
\hline \multicolumn{5}{|l|}{$\begin{array}{l}\text { Right gyrus precentralis (BA 6) right gyrus } \\
\text { postcentralis (BA 43) (+ cluster }\end{array}$} \\
\hline includes parts of $B A 1,2,3,4)$ & $39.9 \pm 1.2$ & $39.5 \pm 0.7$ & $11.0 \pm 5.8$ & $9.5 \pm 2.3$ \\
\hline Right gyrus frontalis inferior (BA 47) & $39.0 \pm 1.3$ & $38.1 \pm 0.8$ & $11.3 \pm 8.3$ & $11.3 \pm 3.2$ \\
\hline \multicolumn{5}{|l|}{ Right midanterior cingulate cortex (BA 24') } \\
\hline (+ cluster includes part of BA 32') & $56.4 \pm 0.7$ & $55.4 \pm 1.4$ & $8.4 \pm 1.4$ & $8.9 \pm 1.7$ \\
\hline Right insula (anterior part) & $62.8 \pm 1.5$ & $61.2 \pm 1.3$ & $8.2 \pm 1.9$ & $8.7 \pm 2.1$ \\
\hline
\end{tabular}

NOTE. Healthy volunteer data are from Vandenberghe et $\mathrm{al}^{15}$ and hypersensitive FD patient data are from the present study. The data were compared with regard to the mean absolute PET signal at baseline (left side) and the mean percentage difference in PET signal between maximal distention and baseline (right side), for each brain area significantly activated in the healthy volunteers.

at baseline and the mean percentage difference in PET signal between maximal distention and baseline for each brain area significantly activated in the healthy volunteers. ${ }^{15}$ None of these differences reached statistical significance. Overall, the right hemisphere dominance of the activation pattern in healthy volunteers was not found in the patient group, showing a more symmetric activation pattern. The right midanterior cingulate cortex and right anterior insula were found only to be significantly activated in the healthy volunteer group. The bilateral gyrus frontalis medialis, left gyrus temporalis inferior, and right gyrus temporalis superior were only found to be activated significantly in the patient group. Both the hypersensitive FD patients and the normosensitive healthy subjects, as a group, showed significant activation of a network including the bilateral gyrus precentralis and postcentralis (sensorimotor cortices), bilateral gyrus frontalis inferior (orbitofrontal cortices), bilateral cerebellar hemisphere, and left gyrus temporalis superior. In the present study, those areas were activated similarly in the hypersensitive FD patients as compared with the healthy volunteers, but this occurred at significantly lower distending pressures, and at similar anxiety and tension scores (Tables 1 and 3).

\section{Discussion}

Previous neuroimaging studies during gastric stimulation have focused on brain activation patterns associated with normal sensitivity ${ }^{13,15,16}$ and satiety ${ }^{14}$ in healthy volunteers. This was a brain imaging study that focused on gastric hypersensitivity, identifying the brain activation patterns associated with painful distention of the proximal stomach in FD patients selected for gastric hypersensitivity. Overall, the observed activation pattern is consistent with, but much more limited than, the "visceral stimulation network," 38 and with the pain circuitry network. ${ }^{39}$ We observed activation of the bilateral sensorimotor cortices (primary somatosensory cortex [S1]/primary motor cortex [M1], BA 4, BA 6), bilateral orbitofrontal cortex (BA 47), bilateral gyrus frontalis medialis (BA 10, BA 11), bilateral gyrus temporalis superior (BA 22, BA 38), bilateral cerebellar hemisphere and left gyrus temporalis inferior (BA 20).

Activation of the right-sided orbitofrontal cortex, particularly the lateral part of the frontal inferior gyrus (BA 47), seems to be relatively specific for gastric stimulation because activation of this area usually was not reported in brain imaging studies during stimulation of other

Figure 1. Rendered image of the right lateral, left lateral, and inferior view of the mean activation pattern during maximal distention relative to baseline (C2-C1). Analysis was run at the $P$ uncorrected value of less than .001. The clusters were projected on the cortical surface of a high-resolution-rendered MRI image. F, frontal; o, occipital; $L$, left; $\mathrm{R}$, right.

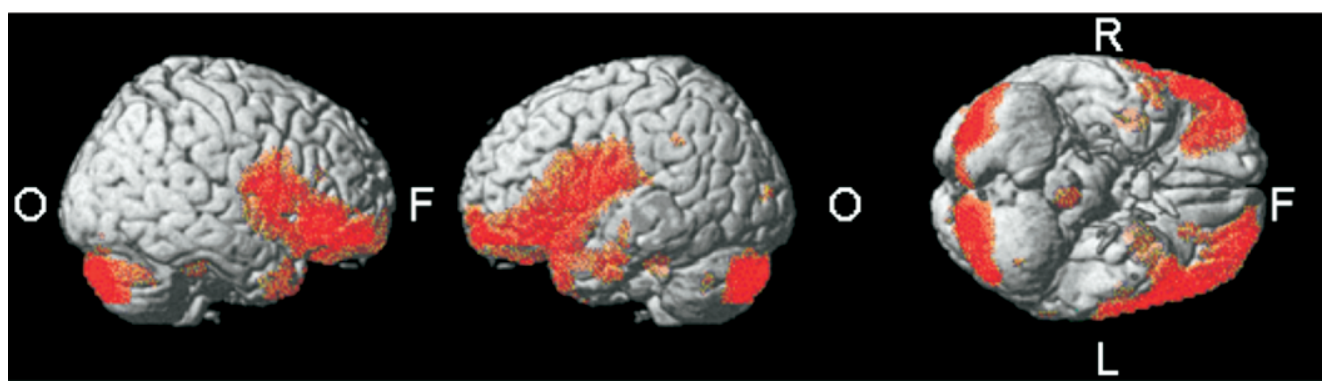




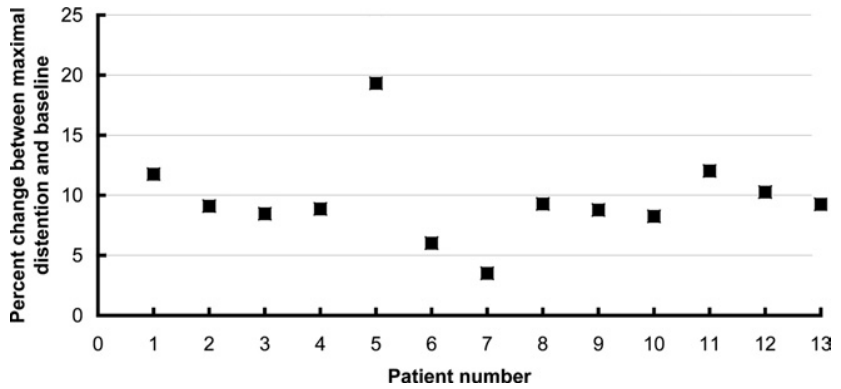

Figure 2. Individual PET signal percentage difference between maximal distention and baseline in the 13 FD patients. For this analysis, a representative and significantly activated brain area was selected: the left gyrus postcentralis.

parts of the gastrointestinal tract. ${ }^{38}$ Activation of the same cortical area also was reported during painful fundus distention ${ }^{15}$ and during nonpainful balloon-induced satiety ${ }^{14}$ in healthy volunteers. The frontal inferior gyrus increasingly is considered a convergence zone for processing food-related stimuli, ${ }^{14}$ which is involved in the regulation of appetite, satiety, and food intake. ${ }^{17-23}$ On the other hand, some studies also reported activation of the (predominantly right-sided) frontal inferior gyrus during rectal distention ${ }^{38}$ in anticipation of an unpleasant picture $^{40}$ and during aversive stimuli, ${ }^{41,42}$ thereby suggesting a broader role for BA 47 in processing or anticipating aversive stimuli.

More generally, the orbitofrontal cortex is viewed as a sensory integration area, monitoring and mapping visceral responses and internal states; appraising sensory, sensorial, and autonomic input in terms of hedonic and reward value; and modulating autonomic and behavioral responses. ${ }^{43}$ Regarding its specific role of evaluating the affective valence of stimuli, a recent meta-analysis ${ }^{44}$ showed differential roles of orbitofrontal cortex subregions. The lateral part of the orbitofrontal cortex encodes for processing and the evaluation of negative affects, negatively rewarded stimuli, negative reinforcers or punishers, and aversion, whereas activity in the medial part is related to the monitoring, learning, and memory of the reward value of reinforcers. In line with this functional differentiation of the lateral and medial orbitofrontal cortex, correlations with pleasantness and hedonic experiences have been found almost exclusively in the medial orbitofrontal cortex..$^{43}$ There is evidence for a posteroanterior distinction of the orbitofrontal cortex, with more complex and abstract reinforcers processed more anteriorly. ${ }^{44}$ The part of the right-sided orbitofrontal cortex that was found to be activated in the present study, BA 47 , with as the primary local maximum the voxel with coordinates $58,40,-10$, is situated in the lateral posterior orbitofrontal cortex, consistent with the processing of a rather simple, aversive, and unpleasant stimulus, namely painful stomach distention, as can be expected on the basis of previous findings. ${ }^{44}$
Surprisingly, we could not show activation of the thalamus, insula, or other structures of the medial pain system, such as the anterior cingulate cortex (ACC). These findings were quite robust because they were replicated in a separate analysis correlating the brain activation pattern with the actual symptom score during that specific scan, which was used as a covariate, instead of subtraction analysis. The absence of activation of these areas, which are considered to be part of the visceral stimulation network, is puzzling because insular activation is reported as the most consistent finding in visceral stimulation research. ${ }^{38}$ The insula is regarded as a key integrative visceral sensory area, mediating affective responses to pain or visceral stimulation. The ACC, on the other hand, is a central cortical area in the medial pain system that encodes for the affective aspects of the pain experience, and comprises not only afferent but also efferent pain modulation pathways.

There are several possible explanations for the lack of significant activation of the insula, thalamus, and ACC. First of all, failure to activate these areas could be of pathophysiologic importance in FD with gastric hypersensitivity and might, for instance, reflect the failure to activate descending antinociceptive pathways in the medial pain system. Generally, the response to aversive or painful stimuli involves co-activation of the ACC and of the lateral orbitofrontal cortex. ${ }^{43}$ In a PET study investigating analgesia and placebo, co-activation of the ACC and of the lateral orbitofrontal cortex was found to be correlated to the placebo response, ${ }^{45}$ which suggests that the analgesic effect of the placebo might be related to the co-activation of these 2 brain areas. ${ }^{46}$ Failure to co-activate both in response to a specific painful stimulus might result in selective hypersensitivity. Aberrant ACC activation in visceral hypersensitivity is widely debated, with conflicting findings reported in the brain-imaging literature on IBS. Several studies have reported lower or absent ACC (BA 24) activation during rectal distention in IBS patients compared with controls, ${ }^{24,47-53}$ whereas other studies have shown higher ACC activation. ${ }^{25,26,54-57}$ Besides methodologic differences and intersubject variability, sex, ${ }^{58}$ abuse history, ${ }^{51}$ and IBS subtypes ${ }^{49}$ are underlying factors that may contribute to the observed heterogeneity.

A second potential explanation for the lack of significant activation of the insula, thalamus, and ACC is differential sensitization of the medial pain system on the one hand, and of the lateral pain system and lateral orbitofrontal cortex on the other hand. If pain intensity sensitivity in the lateral pain system or aversion sensitivity in the orbitofrontal cortex is more up-regulated than sensitivity in the medial pain system, the hypersensitive subject might reach maximum tolerance before the medial pain system is substantially activated. In previous research, we differentiated nonspecific, general hypersensitivity from isolated hyperalgesia and found arguments 
for the former in FD. ${ }^{59}$ The findings of the present study argue for further refinement in the assessment of hypersensitivity and its dimensions, to be able to link hypersensitivity with specific abnormalities in central nervous system pathways.

Third, failure to activate the insula, thalamus, and ACC might reflect the absence of additional recruitment of cortical activity volume with an increasing distention stimulus. This was described in IBS patients, ${ }^{50}$ but in that study it was an overall phenomenon that was not limited to the insula and ACC.

Alternatively, activation in these areas might be increased already in the baseline condition, causing ceiling effects. However, the mean percentage difference in PET signal between maximal distention and baseline was comparable in the insula, as well as ACC and other cortical areas in patients as in healthy subjects (Table 3 ), arguing against ceiling effects.

Finally, heterogeneity of the study group and intersubject variability, combined with a relatively small number of subjects, cannot be discarded as an explanation for the lack of significant activation of the insula, thalamus, and ACC. We aimed to reduce heterogeneity in this study by focusing on FD patients with visceral hypersensitivity. However, even within this group there is still some intersubject variability caused by variability in the localization of activation areas within the insula or anterior cingulate cortex, or by variability of the activation-deactivation intensity within one locus. The subject-by-subject analysis of the difference in signal intensity between distention and baseline in delineated insular and anterior cingulate brain areas confirmed that great variability exists in the present population. On the other hand, when comparing SDs of the mean percentage difference in the PET signal between the maximal distention and baseline in FD and in healthy subjects (Table 3), variability in both groups seems to be comparable in this regard. Furthermore, SDs of the mean percentage difference in the PET signal are certainly not larger in the ACC and the insula as compared with other brain regions (Table 3), suggesting similar or even lower variability in the former brain areas. Elucidating the contribution of this variability to the overall results will require additional studies in greater numbers of similarly characterized patients.

Hypervigilance and anticipation are thought to be major confounders of the assessment of visceral sensitivity of patients with functional bowel disorders. ${ }^{60}$ In a PET study in IBS patients, sham distentions were shown to elicit similar symptoms and brain activation patterns as actual distentions. ${ }^{24}$ In the present study, sham distentions were not associated with higher symptom scores or significant activations in comparison with the baseline condition. This finding questions a major role for anticipation, attention bias, interpretation bias, or response bias in hypersensitive FD patients.
To identify brain activation patterns associated with gastric hypersensitivity, we compared the regions that were activated, and the intensity of activation, in the present study with the results of a similar previous study that we conducted in healthy volunteers. At maximum distention in patients selected for hypersensitivity, bilateral sensorimotor cortices and lateral orbitofrontal cortex were activated similarly as in healthy volunteers, but this occurred at significantly lower distention pressures. Psychologic distress does not seem to explain these relatively higher activation levels in patients because the reported levels of anxiety and tension did not differ between both groups. The similarity of brain activation patterns in the lateral pain system and at significantly lower thresholds than in healthy volunteers might be interpreted as an objective confirmation of the hypersensitivity state in these FD patients, suggestive of higher sensory input, rather than a tendency to more quickly appraise smaller gastric distention stimuli as unpleasant and aversive. Similar activation of the orbitofrontal cortex at lower distending pressures suggests a higher sensory input in the orbitofrontal cortex or a tendency in FD patients to more quickly appraise smaller gastric distention stimuli as unpleasant and aversive, possibly owing to conditioning or learning effects. Alternatively, smaller gastric distention stimuli may induce satiety more easily in these FD patients. The low anxiety scores, the absence of amygdala activation during distention, and the strong activation of lateral orbitofrontal cortex might imply that disgust as a basic emotion is more relevant to FD than anxiety. Disgust and anxiety may mediate effects of psychotrauma or abuse, both associated with $\mathrm{FD},{ }^{11,12}$ on the development of FD.

The major limitation of this study was the relatively invasive procedure used to stimulate the stomach, namely barostat distentions. Introduction of the tube and gastric bag causes not only emotional distress, but also strong vagal activation. We aimed at minimizing the possible impact of this intervention on registered brain activation patterns by leaving at least 2.5 hours between the introduction of the bag and the start of the first scan. However, a certain amount of baseline stimulation by the presence of the assembly and the relatively unpleasant position is unavoidable. Ceiling effects of regional brain activity and concordant regional cerebral blood flow, especially in areas involved in processing aversive and affective stimuli, therefore cannot be ruled out and might result in false negatives. In the areas summarized in Table 3 , however, we found no arguments for ceiling effects (Table 3). Future research should concentrate preferably on more physiologic stimuli, such as the controlled administration of a standardized meal, and offering a less artificial and more gradual stomach distention than balloon inflation. Another potential limitation was the relatively short drug-free period before the PET experiment. A longer drug-free period was not feasible for ethical and 
clinical reasons. Moreover, patients who were taking psychotropics, which can induce long-term central or peripheral nervous system alterations, were excluded from the study.

In summary, we found an important overlap in the activation pattern associated with normal gastric sensitivity and gastric hypersensitivity. We observed that a network including bilateral sensorimotor cortices, bilateral orbitofrontal cortices, bilateral cerebellar hemisphere, and left gyrus temporalis superior is activated similarly during painful proximal stomach distention in hypersensitive FD and in healthy patients, but at much lower distention thresholds in the former, suggesting an objective confirmation of their hypersensitivity status. No statistically significant activation of the ACC, thalamus, and insula was observed in hypersensitive FD patients. This aberrant activation pattern may be indicative of central mechanisms of hypersensitivity, possibly failure of descending antinociceptive pathways. Bilateral gyrus frontalis medialis, left gyrus temporalis inferior, and right gyrus temporalis superior were found to be activated significantly only in the patient group, suggesting more extensive cortical processing in attention- and cognition-related cortical areas. One possible interpretation of this finding is that failure to activate descending antinociceptive pathways results in the recruitment of additional cortical regions that are not activated in normal gastric sensitivity. Anxiety, anticipation, attention bias, interpretation bias, or response bias did not satisfactorily explain the hypersensitivity status and brain activation patterns. The patient sample in the present study was selected for hypersensitivity but still displayed major intersubject variability in brain activation patterns, which may contribute to the lack of significant activation in the ACC, thalamus, and insula in certain areas at a group level analysis.

\section{References}

1. Bradette $M$, Pare $P$, Douville $P$, Morin A. Visceral perception in health and functional dyspepsia. Crossover study of gastric distension with placebo and domperidone. Dig Dis Sci 1991;36: 52-58.

2. Mearin F, Cucala M, Azpiroz F, Malagelada JR. The origin of symptoms on the brain-gut axis in functional dyspepsia. Gastroenterology 1991;101:999-1006.

3. Whitehead WE, Holtkotter B, Enck P, Hoelzl R, Holmes KD, Anthony J, Shabsin HS, Schuster MM. Tolerance for rectosigmoid distention in irritable bowel syndrome. Gastroenterology 1990; 98:1187-1192.

4. Richter JE, Barish CF, Castell DO. Abnormal sensory perception in patients with esophageal chest pain. Gastroenterology 1986;91: 845-852.

5. Sarnelli G, Vandenberghe J, Tack J. Visceral hypersensitivity in functional disorders of the upper gastrointestinal tract. Dig Liver Dis 2004;36:371-376.

6. Lemann M, Dederding JP, Flourie B, Franchisseur C, Rambaud JC, Jian R. Abnormal perception of visceral pain in response to gastric distension in chronic idiopathic dyspepsia. The irritable stomach syndrome. Dig Dis Sci 1991;36:1249-1254.
7. Tack J, Caenepeel P, Fischler B, Piessevaux H, Janssens J. Symptoms associated with hypersensitivity to gastric distention in functional dyspepsia. Gastroenterology 2001;121:526-535.

8. Boeckxstaens GE, Hirsch DP, Kuiken SD, Heisterkamp SH, Tytgat GN. The proximal stomach and postprandial symptoms in functional dyspeptics. Am J Gastroenterol 2002;97:40-48.

9. Rhee PL, Kim YH, Son HJ, Kim JJ, Koh KC, Paik SW, Rhee JC, Choi $\mathrm{KW}$. Evaluation of individual symptoms cannot predict presence of gastric hypersensitivity in functional dyspepsia. Dig Dis Sci 2000;45:1680-1684.

10. Fischler B, Tack J, De Gucht V, Shkedy ZI, Persoons P, Broekaert D, Molenberghs G, Janssens J. Heterogeneity of symptom pattern, psychosocial factors, and pathophysiological mechanisms in severe functional dyspepsia. Gastroenterology 2003;124: 903-910.

11. Van Oudenhove L, Vandenberghe J, Geeraerts B, Vos R, Persoons P, Demyttenaere K, Fischler B, Tack J. The relationship between anxiety and gastric sensorimotor function in functional dyspepsia. Psychosomatic Medicine. In press.

12. Geeraerts B, Van Oudenhove L, Fischler B, Vandenberghe J, Caenepeel P, Janssens J, Tack J. The association between gastric sensorimotor function and abuse history in functional dyspepsia. Gastroenterology 2005;128:A339 (abstr).

13. Ladabaum U, Minoshima S, Hasler WL, Cross D, Chey WD, Owyang C. Gastric distention correlates with activation of multiple cortical and subcortical regions. Gastroenterology 2001;120: 369-376.

14. Stephan E, Pardo JV, Faris PL, Hartman BK, Kim SW, Ivanov EH, Daughters RS, Costello PA, Goodale RL. Functional neuroimaging of gastric distention. J Gastrointest Surg 2003;7:740-749.

15. Vandenberghe J, Dupont P, Fischler B, Bormans G, Persoons P, Janssens J, Tack J. Regional brain activation during proximal stomach distention in humans: a positron emission tomography study. Gastroenterology 2005;128:564-573.

16. Lu CL, Wu YT, Yeh TC, Chen LF, Chang FY, Lee SD, Ho LT, Hsieh JC. Neuronal correlates of gastric pain induced by fundus distension: a 3T-fMRI study. Neurogastroenterol Motil 2004;16:575587.

17. Morris JS, Dolan RJ. Involvement of human amygdala and orbitofrontal cortex in hunger-enhanced memory for food stimuli. J Neurosci 2001;21:5304-5310.

18. Gautier JF, Chen K, Salbe AD, Bandy D, Pratley RE, Heiman M, Ravussin E, Reiman EM, Tataranni PA. Differential brain responses to satiation in obese and lean men. Diabetes 2000;49: 838-846.

19. Gautier JF, Del Parigi A, Chen K, Salbe AD, Bandy D, Pratley RE, Ravussin E, Reiman EM, Tataranni PA. Effect of satiation on brain activity in obese and lean women. Obes Res 2001;9:676-684.

20. O'Doherty J, Rolls ET, Francis S, Bowtell R, McGlone F, Kobal G, Renner B, Ahne G. Sensory-specific satiety-related olfactory activation of the human orbitofrontal cortex. Neuroreport 2000;11: 399-403.

21. Karhunen LJ, Vanninen EJ, Kuikka JT, Lappalainen RI, Tiihonen J, Uusitupa MI. Regional cerebral blood flow during exposure to food in obese binge eating women. Psychiatry Res 2000;99: 29-42.

22. Del Parigi A, Chen K, Gautier JF, Salbe AD, Pratley RE, Ravussin E, Reiman EM, Tataranni PA. Sex differences in the human brain's response to hunger and satiation. Am J Clin Nutr 2002; 75:1017-1022.

23. Tataranni PA, Gautier JF, Chen K, Uecker A, Bandy D, Salbe AD, Pratley RE, Lawson M, Reiman EM, Ravussin E. Neuroanatomical correlates of hunger and satiation in humans using positron emission tomography. Proc Natl Acad Sci U S A 1999;96:4569 4574. 
24. Silverman DH, Munakata JA, Ennes H, Mandelkern MA, Hoh CK, Mayer EA. Regional cerebral activity in normal and pathological perception of visceral pain. Gastroenterology 1997;112:64-72.

25. Mertz H, Morgan V, Tanner G, Pickens D, Price R, Shyr Y, Kessler R. Regional cerebral activation in irritable bowel syndrome and control subjects with painful and nonpainful rectal distention. Gastroenterology 2000;118:842-848.

26. Naliboff BD, Derbyshire SWG, Munakata J, et al. Cerebral activation in irritable bowel syndrome patients and control subjects during rectosigmoid stimulation. Psychosom Med 2001;63:365-375.

27. Fox PT, Mintun MA, Raichle ME, Miezin FM, Allman JM, Van Essen DC. Mapping human visual cortex with positron emission tomography. Nature 1986;323:806-809.

28. Brix G, Zaers J, Adam LE, Bellemann ME, Ostertag H, Trojan H, Haberkorn U, Doll J, Oberdorfer F, Lorenz WJ. Performance evaluation of a whole-body PET scanner using the NEMA protocol. National Electrical Manufacturers Association. J Nucl Med 1997; 38:1614-1623.

29. Kinahan P, Rogers J. Analytic three-dimensional image reconstruction using all detected events. Trans Nucl Sci 1989;36:964-968.

30. Friston K, Ashburner J, Poline J, Frith C, Heather J, Frackowiak R. Spatial realignment and normalization of images. Hum Brain Map 1995;3:165-189.

31. Friston KJ, Frith CD, Liddle PF, Frackowiak RS. Comparing functional (PET) images: the assessment of significant change. J Cereb Blood Flow Metab 1991;11:690-699.

32. Friston K, Worsley K, Frackowiak R, Mazziotta J, Evans A. Assessing the significance of focal activations using their spatial extent. Hum Brain Map 1994;1:214-220.

33. Worsley KJ, Evans AC, Marrett S, Neelin P. A three-dimensional statistical analysis for CBF activation studies in human brain. J Cereb Blood Flow Metab 1992;12:900-918.

34. Friston K, Holmes A, Worsley K, Poline J, Frith C. Statistical parametric maps in human functional imaging: a general linear approach. Hum Brain Map 1995;23:189-210.

35. Mugler JP 3rd, Brookeman JR. Three-dimensional magnetizationprepared rapid gradient-echo imaging (3D MP RAGE). Magn Reson Med 1990;15:152-157.

36. Maes F, Collignon A, Vandermeulen D, Marchal G, Suetens P. Multimodality image registration by maximization of mutual information. IEEE Trans Med Imaging 1997;16:187-198.

37. Talairach J, Tournoux P. Co-planar stereotaxic atlas of the human brain. Stuttgart, Germany; Georg Thieme, 1988.

38. Derbyshire SW. A systematic review of neuroimaging data during visceral stimulation. Am J Gastroenterol 2003;98:12-20.

39. Peyron R, Laurent B, Garcia-Larrea L. Functional imaging of brain responses to pain. A review and meta-analysis (2000). Neurophysiol Clin 2000;30:263-288.

40. Ueda K, Okamoto Y, Okada G, Yamashita H, Hori T, Yamawaki S. Brain activity during expectancy of emotional stimuli: an fMRI study. Neuroreport 2003;14:51-55.

41. Rolls ET, O'Doherty J, Kringelbach ML, Francis S, Bowtell R, McGlone F. Representations of pleasant and painful touch in the human orbitofrontal and cingulate cortices. Cereb Cortex 2003; 13:308-317.

42. O'Doherty J, Rolls ET, Francis S, Bowtell R, McGlone F. Representation of pleasant and aversive taste in the human brain. J Neurophysiol 2001;85:1315-1321.

43. Kringelbach ML. The human orbitofrontal cortex: linking reward to hedonic experience. Nat Rev Neurosci 2005;6:691-702.

44. Kringelbach ML, Rolls ET. The functional neuroanatomy of the human orbitofrontal cortex: evidence from neuroimaging and neuropsychology. Prog Neurobiol 2004;72:341-372.

45. Petrovic P, Kalso E, Petersson KM, Ingvar M. Placebo and opioid analgesia-imaging a shared neuronal network. Science 2002; 295:1737-1740.
46. Petrovic $\mathrm{P}$, Ingvar $\mathrm{M}$. Imaging cognitive modulation of pain processing. Pain 2002;95:1-5.

47. Andresen V, Bach DR, Poellinger A, Tsrouya C, Stroh A, Foerschler A, Georgiewa P, Zimmer C, Monnikes H. Brain activation responses to subliminal or supraliminal rectal stimuli and to auditory stimuli in irritable bowel syndrome. Neurogastroenterol Motil 2005;17:827-837.

48. Kwan CL, Diamant NE, Mikula K, Davis KD. Characteristics of rectal perception are altered in irritable bowel syndrome. Pain 2005;113:160-171.

49. Wilder-Smith CH, Schindler D, Lovblad K, Redmond SM, Nirkko A. Brain functional magnetic resonance imaging of rectal pain and activation of endogenous inhibitory mechanisms in irritable bowel syndrome patient subgroups and healthy controls. Gut 2004;53:1595-1601.

50. Sidhu H, Kern M, Shaker R. Absence of increasing cortical fMRI activity volume in response to increasing visceral stimulation in IBS patients. Am J Physiol 2004;287:G425-G435.

51. Ringel Y, Drossman DA, Turkington TG, Bradshaw B, Hawk TC, Bangdiwala S, Coleman RE, Whitehead WE. Regional brain activation in response to rectal distension in patients with irritable bowel syndrome and the effect of a history of abuse. Dig Dis Sci 2003;48:1774-1781.

52. Bonaz B, Baciu M, Papillon E, Bost R, Gueddah N, Le Bas JF, Fournet J, Segebarth C. Central processing of rectal pain in patients with irritable bowel syndrome: an fMRI study. Am J Gastroenterol 2002;97:654-661.

53. Bernstein CN, Frankenstein UN, Rawsthorne P, Pitz M, Summers $\mathrm{R}$, McIntyre MC. Cortical mapping of visceral pain in patients with Gl disorders using functional magnetic resonance imaging. Am J Gastroenterol 2002;97:319-327.

54. Lawal A, Kern M, Sidhu H, Hofmann C, Shaker R. Novel evidence for hypersensitivity of visceral sensory neural circuitry in irritable bowel syndrome patients. Gastroenterology 2006;130:26-33.

55. Mayer EA, Berman S, Suyenobu B, Labus J, Mandelkern MA, Naliboff BD, Chang L. Differences in brain responses to visceral pain between patients with irritable bowel syndrome and ulcerative colitis. Pain 2005;115:398-409.

56. Yuan YZ, Tao RJ, Xu B, Sun J, Chen KM, Miao F, Zhang ZW, Xu JY. Functional brain imaging in irritable bowel syndrome with rectal balloon-distention by using fMRI. World J Gastroenterol 2003;9: 1356-1360.

57. Verne GN, Himes NC, Robinson ME, Gopinath KS, Briggs RW, Crosson B, Price DD. Central representation of visceral and cutaneous hypersensitivity in the irritable bowel syndrome. Pain 2003;103:99-110.

58. Berman S, Munakata J, Naliboff BD, Chang L, Mandelkern M, Silverman D, Kovalik E, Mayer EA. Gender differences in regional brain response to visceral pressure in IBS patients. Eur J Pain 2000;4:157-172.

59. Vandenberghe J, Vos R, Persoons P, Demyttenaere K, Janssens $J$, Tack J. Sensitisation of pain-specific or multimodal afferent pathways in dyspeptic patients with visceral hyperalgesia. Gut 2005;54:914-919.

60. Naliboff BD, Munakata J, Fullerton S, Gracely RH, Kodner A, Harraf F, Mayer EA. Evidence for two distinct perceptual alterations in irritable bowel syndrome. Gut 1997;41:505-512.

Received July 25, 2006. Accepted January 24, 2007.

Address requests for reprints to: Jan Tack, MD, PhD, Department of Internal Medicine, Division of Gastroenterology, University Hospital Gasthuisberg, Herestraat 49, B-3000 Leuven, Belgium. e-mail: Jan.Tack@med.kuleuven.ac.be; fax: (32) 16-34-44-19.

Supported by a grant from the Fund for Scientific Research, Flanders, Belgium. 